\title{
Autecology of Melastoma malabathricum, an invasive species in the Way Kambas National Park, Indonesia
}

\author{
JANI MASTER ${ }^{1}$, IBNUL QAYIM ${ }^{2, \boldsymbol{\vartheta}}$, DEDE SETIADI ${ }^{2}$, NYOTO SANTOSO ${ }^{3}$ \\ ${ }^{1}$ Plant Biology Graduate Program, Department of Biology, Faculty of Mathematics and Natural Science, Institut Pertanian Bogor. Jl. Meranti, Dramaga, \\ Bogor 16680, West Java, Indonesia \\ ${ }^{2}$ Department of Biology, Faculty of Mathematics and Natural, Institut Pertanian Bogor. Jl. Meranti, Dramaga, Bogor, 16680 West Java, Indonesia. \\ Tel./fax.: +62251-8622642. "email: i-qayim@apps.ipb.ac.id \\ ${ }^{3}$ Department of Forest Resources Conservation and Ecotourism, Faculty of Forestry, Institut Pertanian Bogor. Jl. Ulin, Kampus Dramaga, Bogor 16680 , \\ West Java, Indonesia
}

Manuscript received: 19 March 2020. Revision accepted: 29 April 2020.

\begin{abstract}
Master J, Qayim I, Setiadi D, Santoso N. 2020. Autecology of Melastoma malabathricum, an invasive species in the Way Kambas National Park, Indonesia. Biodiversitas 21: 2303-2310. Melastoma malabathricum has become one of the invasive plants in the Way Kambas National Park (WKNP), Lampung, Indonesia. This plant is feared to be a problem in efforts to conserve biodiversity in the WKNP area. Therefore, this study aimed to analyze the factors causing the invasion of these plants. The vegetation analysis plot was placed on three types of habitats in the study location, namely, forests, swamps, and invaded swamps, then measurements and records of vegetation data and abiotic factors were recorded in each plot. The results reveal that M. malabathricum dominates swamp habitat and negatively associated with trees, which can provide canopy. Abiotic factors, such as canopy cover, water level, and soil fertility, become supporting factors for the invasion. In addition, climate change, which is causing drought also contributes to the invasion of $M$. malabathricum at the WKNP.
\end{abstract}

Keywords: Biotic and abiotic factors, conservation, invasive species, vegetation analysis

\section{INTRODUCTION}

The presence of invasive species in conservation areas has become a serious problem for biodiversity conservation efforts. Species invasion is caused by complex system. Therefore, autecology is one of the keys to investigate the cause of species invasion in a conservation area. Autecology is a study to investigate the relationship between a species and its environment (Jongman et al. 1987; Bambach et al. 2007). The autecology concept has the advantage of generalization to answer the various problems posed by a species (Walter and Hangeveld 2014). According to Sutomo and Fardila (2015), the information was generated by study of invasive species autecology will act as baseline data for determining the control strategies of invasion in an area. Nowadays, several conservation areas in Indonesia face challenges of the presence of invasive species, for example in Way Kambas National Park (WKNP), Lampung Province, Indonesia.

The biodiversity of the WKNP cannot be separated from various problems in management, one of which is the presence of invasive plant species. Invasive alien plants are plants that live outside their natural habitat and are able to dominate in these habitats because they do not have natural enemies. These plants have a negative impact on local species, habitat, and human interests. In certain cases, invasions by local plant species occurred, such as the Merremia peltata invasion in Bukit Barisan Selatan National Park (Master 2013) and the Arenga obtusifolia invasion in Ujung Kulon National Park (Padmanaba et al.
2017). This is certainly a serious problem for conservation efforts in Indonesia.

One type of plant that has invaded the WKNP is Melastoma malabathricum L.. Moreover, conservation areas were invaded by $M$. malabathricum, such as in Tanjung Puting National Park and Pangandaran Nature Reserve (Rosleine and Suzuki 2012). The invasion of a plant species in a conservation area causes many problems, such as disturbance to animal habitat, the decrease in biodiversity, and the decrease in habitat carrying capacity (Gallardo et al. 2016; Broadbent et al. 2018).

The impact of species invasion is not immediately visible; therefore, efforts to prevent and control biological invasion must be expended as early as possible. The first step or effort to control species invasion is to study their ecological character, because the causes of species invasion are usually unique, so it is important to understand the autecology of these invasive types (Sutomo and Fardila 2015).

In this study, the measurement and analysis of biotic and abiotic factors that were suspected to be the cause of the M. malabathricum invasion in the WKNP were performed. This study has important value because the data generated in studying the autecology of invasive species will be useful as a baseline for planning management programs, namely, rehabilitation and restoration of the area. Until now, there were no studies or researches on $M$. malabathricum invasion in the WKNP. Therefore, this study aimed to analyze the biotic and abiotic factors that cause the M. malabathricum invasion in the WKNP. 


\section{MATERIALS AND METHODS}

\section{Research Location and Sampling of Plot Design}

Research was conducted at the Kalibiru Swamp, Way Kambas National Park (WKNP), Lampung Province, Indonesia, and divided into three habitat types, namely, forest, swamp, and invaded swamp. M. malabathricum invades most of the swamp habitat in the Kalibiru; therefore, research is conducted on the invaded swamp habitat, comparing it with non-invaded swamps and forests in the national park.

Vegetation sampling was performed by making three 200-m stubs along the swamp, M. malabathricum-invaded swamp, and forest habitat, so that information on the condition of each habitat was obtained. In each of the stub paths, vegetation plots were placed intermittently (Figure 1). Vegetation plots were made with a size of $20 \times 20 \mathrm{~m}$ for tree-level ( dbh $>20 \mathrm{~cm}), 10 \times 10 \mathrm{~m}$ for pole level ( $\mathrm{dbh} 10$ $20 \mathrm{~cm}$ ), $5 \times 5 \mathrm{~m}$ for sapling level (height $>1.5 \mathrm{~m}$ and dbh < $10 \mathrm{~cm}$ ), and $2 \times 2 \mathrm{~m}$ for seedlings (from sprouts to $1.5 \mathrm{~m}$ high) and understory (shrubs and small trees) (Krebs 1989). Soil sampling was also performed in a composite manner representing the three habitats.

This research did not study anthropological factors and events, such as forest fires, that might affect Melastoma invasion in the WKNP. Research is focused on the interaction between biotic and abiotic factors that can support M. malabathricum invasion in the WKNP.

\section{Biotic factor measurement}

Biotic factor measurement is for plant species and animals. Herbarium species identification was performed at the Herbarium Bogoriense (BO), Research Center for Biology -Indonesian Institute of Sciences (LIPI). There are two types of observation of animal activities in invaded habitats: first is direct observation, in which activities of animals found in invaded habitats are observed, and second is indirect observation, in which secondary signs left behind, such as traces and dirt, are being looked at. Observations were performed for 5 days each month, starting from January to November 2019.The observations were presented descriptively.

\section{Abiotic factor measurement}

Abiotic factor measurement of M. malabathricum invasion was performed in April 2018, whereas measurements of tidal swamps were performed from January to November 2019 using Peilschaal water level boards, which were placed in the middle of the swamp. The water level was recorded in the morning and evening for 5 days per month. Other data recorded were dbh, temperature and humidity, water level, distance of the plot from the river, percentage of canopy cover measured using a concave densitometer, and light intensity measured using a digital lux meter. Soil chemical analysis was conducted at the Soil Laboratory of the Soil Research Institute, Agricultural Research and Development Agency, Bogor, Indonesia.

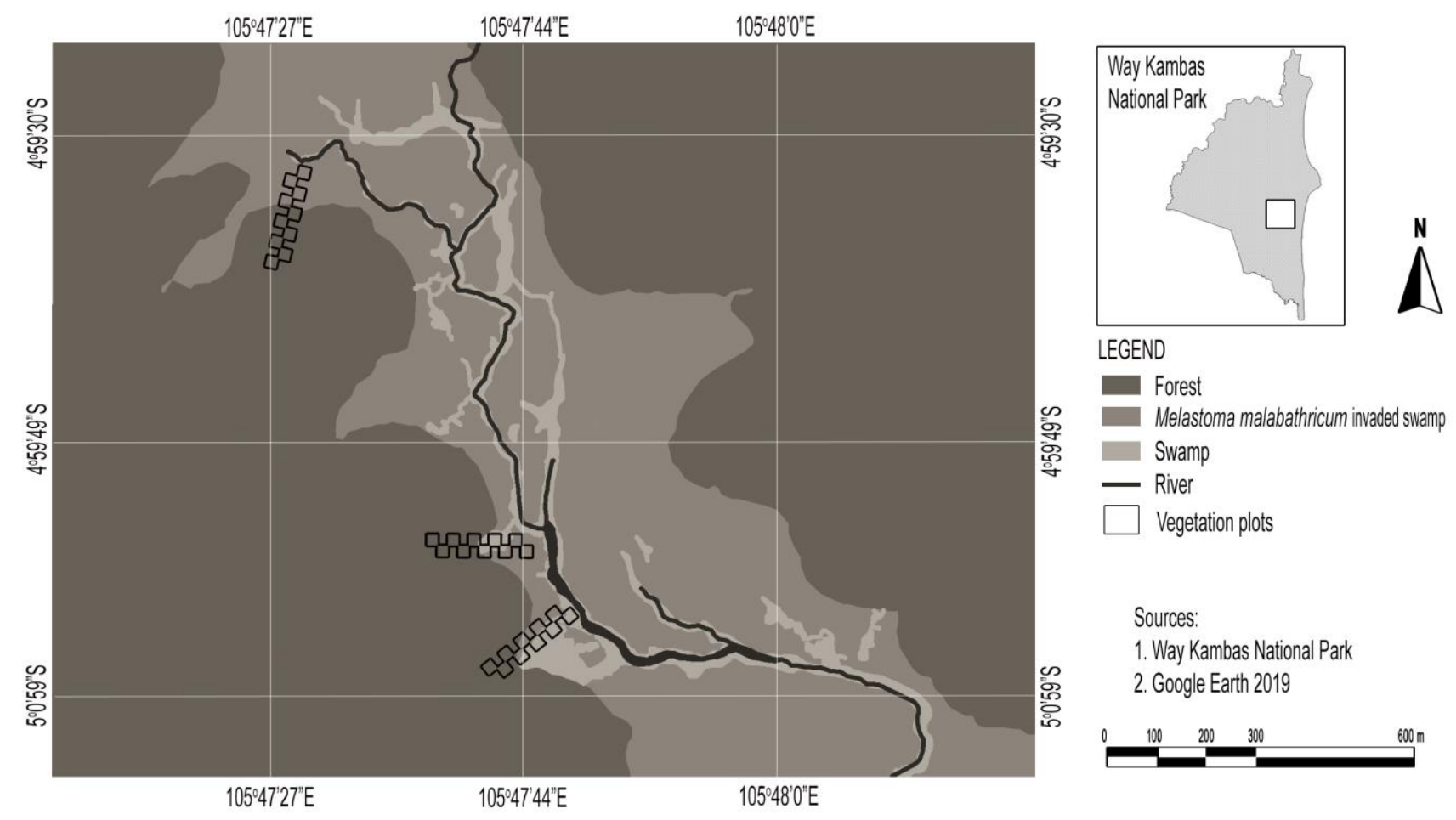

Figure 1. Research location and placement design of vegetation analysis plot in the Kalibiru Swamp, Way Kambas National Park (WKNP), Lampung Province, Indonesia 


\section{Data analysis}

Vegetation data were analyzed by calculating the Shannon-Wiener diversity index, evenness index, and important value index (IVI). Associated analysis was conducted on all plant species found in the vegetation analysis plot in the invaded swamp and swamp habitat using a $2 \times 2$ contingency table and tested using chisquared $\left(\chi^{2}\right)$ test (Ludwig and Reynolds 1988). The principal component and biplot analyses were also conducted to determine the abiotic factors that influence $M$. malabathricum invasion in WKNP. In order to investigate the main factor that causes M. malabathricum invasion at WKNP, the data were also analyzed descriptively by comparing the measurement of the biotic and abiotic factors of three observed habitat types.

\section{RESULTS AND DISCUSSION}

\section{Melastoma malabathricum invasion and animal's role}

Melastoma malabathricum is a plant with shrub habitus and has a stem height of 0.5-5 m (Ling et al. 2009). In the WKNP, this plant has a height of up to $2.1 \mathrm{~m}$, with density reaching 30 individuals $/ \mathrm{m}^{2}$. M. malabathricum in the WKNP grows in an open location and in groups. The Kalibiru Swamp has the largest area (123.27 hectares or $88 \%$ of the swamp area) covered by $M$. malabathricum in the WKNP.

The Kalibiru Swamp is a tidal swamp with a river in the middle, which recedes during the dry season, whereas during the rainy season, the water overflows, filling the swamp. Before being invaded by $M$. malabathricum, the Kalibiru Swamp was an important location for the survival of animals in the WKNP, especially for ungulates, because it provided food in the form of grass that was always green. In addition, this swamp was a habitat for various types of water birds (Parrott and Andrew 2011). At present, the grass, which is the source of food for ungulates, has difficulty growing due to the invasion. The area of the grassland was estimated to be only $12 \%$. This results in the decrease in the activities of ungulates, such as the sambar deer (Cervus unicolor), at that location due to a decrease in the carrying capacity of the habitat in terms of food availability.

During the observation, there was no browser animal (herbivory) activity that ate the $M$. malabathricum plant part. Browser animals found at the study site, such as the sambar deer, only ate a few types of grass in that location. The palatability of the sambar deer to plants from the Melastomataceae family was very low, so that $M$. malabathricum in this location was able to grow well without being controlled by any animals (Ismail and Jiwan 2015). This condition also occurred in Pangandaran Nature Reserve (PNR), the deer left the invaded location to look for food sources in other places (Rosleine and Suzuki 2012). If $M$. malabathricum invasion in the Kalibiru Swamp continues, it will have an impact on the survival of animals in that location. M. malabathricum invasion was also assisted by several types of animals by spreading the seeds of these plants. The animals suspected to be the seedspreading agents were fruit-eating birds, such as Pycnonotus goiavier and P. simplex.

\section{Vegetation composition and biotic factors of invasion}

Based on the condition of vegetation cover, the research location in Kalibiru, WKNP in this study was divided into three types of habitats, namely, forests, swamp, and invaded swamp by $M$. malabathricum. The forest is the edge of swamp area that had been grown by trees, this habitat surrounds Kalibiru area and still exposed to the tidal swamp. Swamp habitat is an open tidal swamp without either $M$. malabathricum or other plant species. Invaded swamp is area that had been covered by M. malabathricum (Figure 1).

The forest had a high diversity index for the categories of trees, saplings, seedlings, and undergrowth compared with the other two habitats. As for the pole category, the highest diversity index was in the swamp habitat (Table 1). The invaded swamp habitat had the lowest diversity value, although the diversity index of understory in this location was higher than that of the swamp, but the evenness index was lower, which means that there was dominance of certain types of plants at that location. The dominant plant was $M$. malabathricum, because of all the plant species in the location, $M$. malabathricum had the highest IVI (88.82). In the swamp habitat, M. malabathricum also had the highest IVI (95.56), but the evenness index in the habitat was higher than that of the invaded swamp. It means that the dominance of $M$. malabathricum in that location was not as great as that in the invaded swamp.

The dominance of $M$. malabathricum was caused by the small number of plants that can grow under the $M$. malabathricum stand; it is related to competition for light and the presence of allelopathic chemicals released by $M$. malabathricum. Sarma et al. (2019) stated that $M$. malabathricum produces allelopathic chemicals, which can reduce the rate of germination and elongation of roots and shoots of grass.

Melastoma malabathricum was not found in the forest. The canopy cover can prevent sunlight needed by $M$. malabathricum to germinate and grow. M. malabathricum seeds can be spread into the forest, but they are unlikely to grow because of lack of ecological requirements in the form of insufficient light.

The competition for light was also tested, which can be seen in the analysis of the association between $M$. malabathricum and other plants. A total of 14 plant species found in invaded swamps and swamps were tested to investigate their association with $M$. malabathricum (Table 2 ). The results revealed that seven species of plants were negatively associated with $M$. malabathricum, i.e.: Barringtonia reticulate, Calophyllum calaba, Leea sp., Madhuca motleyana, Neolitsea zeylanica, Syzygium densiflora, and Syzygium racemosum. All species associated with $M$. malabathricum are the types of plants that can form a canopy, hence blocking the light needed by M. malabathricum. The negative association presented in Table 2 indicates that between each species, there was a competition over the use of resources. It can be seen in the increasing growth, or the number of individuals that will suppress the growth of other species. Negative association indicates that there was no tolerance for living together or there was no reciprocal relationship that was mutually beneficial, especially in the division of living space. 
Table 1. Diversity index (H') and evenness index (E) of the different types of habitat in the Kalibiru Swamp, Way Kambas National Park, Lampung Province, Indonesia

\begin{tabular}{lcccccccccc}
\hline & \multicolumn{2}{c}{ Tree } & \multicolumn{2}{c}{ Pole } & \multicolumn{2}{c}{ Sapling } & \multicolumn{2}{c}{ Seedling } & \multicolumn{2}{c}{ Undergrowth } \\
\cline { 2 - 11 } & $\mathbf{H}^{\prime}$ & $\mathbf{E}$ & $\mathbf{H}^{\prime}$ & $\mathbf{E}$ & $\mathbf{H}^{\prime}$ & $\mathbf{E}$ & $\mathbf{H}^{\prime}$ & $\mathbf{E}$ & $\mathbf{H}^{\prime}$ & $\mathbf{E}$ \\
\hline Forest & 2.45 & 0.76 & 1.66 & 0.80 & 2.34 & 0.80 & 1.49 & 0.48 & 1.54 & 0.96 \\
Swamp & 0.35 & 0.50 & 1.98 & 0.95 & 1.39 & 1.00 & 0.00 & 0.00 & 0.94 & 0.85 \\
Invaded swamp & 0.00 & 0.00 & 0.00 & 0.00 & 0.69 & 1.00 & 0.00 & 0.00 & 1.08 & 0.67 \\
\hline
\end{tabular}

Table 2. The results of the association analysis between Melastoma malabathricum and plants found in the vegetation analysis plot using a $2 \times 2$ contingency table and chi-squared $\left(\chi^{2}\right)$ test

\begin{tabular}{llll}
\hline \multicolumn{1}{c}{ Species } & Chi-square $\left(\chi^{\mathbf{2}}\right)$ & Association & Jaccard Index \\
\hline Barringtonia reticulate & $6.35 *$ & Negative & 0.13 \\
Calophyllum calaba & $9.23 * *$ & Negative & 0.07 \\
Chromolaena odorata & 0.16 & Not associated & - \\
Cinnamomum iners & 0.16 & Not associated & - \\
Cyperus sp. & 2.64 & Not associated & - \\
Eleocharis dulcis & 0.36 & Not associated & - \\
Fimbristylis ovate & 1.15 & Not associated & - \\
Isachne globosa & 1.30 & Not associated & - \\
Leea sp. & $15.00 * *$ & Negative & 0.00 \\
Madhuca motleyana & $15.00 * *$ & Negative & 0.00 \\
Neolitsea zeylanica & $4.62 *$ & Negative & 0.20 \\
Rourea minor & 1.15 & Not associated & - \\
Syzygium densiflora & $15.00 * *$ & Negative & 0.00 \\
Syzygium racemosum & $15.00 * *$ & Negative & 0.00 \\
\hline Note: $*$ significant at $\alpha 0.05 ; *$ significant at $\alpha 0.01$ & & \\
\end{tabular}

Note: *significant at $\alpha 0.05 ; * *$ significant at $\alpha 0.01$

\section{Abiotic factors of Melastoma malabathricum invasion}

The essential nutrients in the form of $\mathrm{P}_{2} \mathrm{O}_{5}, \mathrm{~K}_{2} \mathrm{O}, \mathrm{Mg}$, $\mathrm{Na}$, and cation-exchange capacity (CEC) exhibited lower values at the invaded location than at the non-invaded swamp (Table 3). Likewise, with the $\mathrm{C} / \mathrm{N}$ ratio at the invaded location, it had lower soil fertility compared with the non-invaded swamp. The low $\mathrm{C} / \mathrm{N}$ ratio indicated a slower rate of organic matter turnover. If it had slower turnover, then there would also be a delayed release of nutrients, especially nitrogen, whereas low CEC at the invaded location caused nutrients to be easily washed away by water. Poor soil condition was not a barrier for $M$. malabathricum, because these plants were able to live in nutrient-poor land (Isnaniarti et al. 2017).

The acidity level of the soil is one of the factors causing M. malabathricum invasion, because the plant is resistant to acid stress (Claveria et al. 2019), but the results of the soil chemical analysis did not reveal significant differences in the $\mathrm{pH}$ values between the three study sites (Table 3 ). Even so, the $\mathrm{K}, \mathrm{Ca}$, and $\mathrm{Mg}$ values in the invaded location were very low, increasing the potential of the soil to become acidic. In addition, the aluminum ( $\mathrm{Al})$ content in the invaded location was higher than in other locations, although the difference in values was not too high. However, this condition caused M. malabathricum to grow better than the other plant species, because $M$. malabathricum is resistant to $\mathrm{Al}$ stress and had the highest $\mathrm{Al}$ accumulator (14.4 mg.g ${ }^{-1}$ leaves dry weight) without causing growth abnormalities (Mahmud and Burslem 2018). $\mathrm{Al}^{3+}$ content also contributes to soil acidity. Another potential source of soil acidity in the invaded swamp was pyrite $\left(\mathrm{FeS}_{2}\right)$. In this location, the pyrite content had a higher value than non-invaded swamp or forest.

The principal component analysis on the factors of environmental conditions succeeded in reducing eight environmental factors to six, which were grouped into two main components. The components were able to explain all environmental factors measured (Tables 4 and 5). The first component was able to explain $81.63 \%$ of all the environmental factors measured, whereas the second component only explained at $18.36 \%$. The proportion value of the two components from the analysis of the main components indicated that the first component provided relatively greater information compared with the second in describing the environmental conditions of $M$. malabathricum invasion. Canopy cover, air humidity, and distance from the river were the variables that had a negative influence, whereas the air temperature and substrate temperature were variables that had a positive influence on the first component factor. Moreover, the $\mathrm{pH}$ of the substrate was the most influential variable on the second component factor.

The interaction of the environmental parameters in the three habitat conditions based on the analysis of the main components can be explained using a biplot. In quadrant I, the swamp habitat was correlated with the $\mathrm{pH}$ of the substrate and water level. The vectors had positive correlations. Although these correlations were not so strong, they were represented by angles that were not overly narrow. The swamp had a higher water level than the invaded swamp and forest. In quadrant II, the invaded swamp positively correlated with air temperature, substrate 
temperature, and sunlight intensity and had an open canopy condition, so that the light intensity was higher, causing the substrate temperature and air temperature to be higher than in other locations. Also, the forest in quadrant IV had the farthest distance from the river and a dense canopy cover, so that the humidity was also high (Figure 2).

Table 4. Characteristic matrix value of the correlation between the three habitat conditions and the environmental factors in the Way Kambas National Park, Lampung Province, Indonesia

\begin{tabular}{cccc}
\hline \multirow{2}{*}{ Component } & \multicolumn{3}{c}{ Initial Eigen Values } \\
\cline { 2 - 4 } & Total & \% Diversity & $\begin{array}{c}\text { \% Cumulative } \\
\text { diversity }\end{array}$ \\
\hline 1 & 6.5309 & 81.6365 & 81.6365 \\
2 & 1.4690 & 18.3634 & 100 \\
\hline
\end{tabular}

Table 5. Environmental factors of invasion in the Kalibiru Swamp, Way Kambas National Park, Lampung Province, Indonesia

\begin{tabular}{lcc}
\hline \multicolumn{1}{c}{ Variable } & Component $\mathbf{1}$ & Component 2 \\
\hline Canopy cover & $\mathbf{- 0 . 9 9 9 7}$ & 0.0209 \\
Distance from the river & $\mathbf{- 0 . 9 8 7 5}$ & 0.1575 \\
Water level & 0.7958 & 0.6055 \\
Light intensity & 0.8993 & -0.4372 \\
Air temperature & $\mathbf{0 . 9 9 9 4}$ & -0.0323 \\
Substrate temperature & $\mathbf{0 . 9 9 5 9}$ & -0.0896 \\
Humidity & $\mathbf{- 0 . 9 8 9 8}$ & 0.1424 \\
pH of substrate & 0.3787 & $\mathbf{0 . 9 2 5 5}$ \\
\hline
\end{tabular}

Table 3. Comparison of soil chemical properties at the three study sites in the Way Kambas National Park, Lampung Province, Indonesia (criteria by the Central Bureau of Statistics 2012)

\begin{tabular}{|c|c|c|c|c|c|c|}
\hline \multirow[t]{2}{*}{ Edaphic factors } & \multicolumn{2}{|c|}{$\begin{array}{l}\text { Invaded M. malabathricum } \\
\text { swamp }\end{array}$} & \multicolumn{2}{|c|}{ Swamp } & \multicolumn{2}{|c|}{ Forest } \\
\hline & Value & Criteria & Value & Criteria & Value & Criteria \\
\hline $\mathrm{pH}\left(\mathrm{H}_{2} \mathrm{O}\right)$ & 4.90 & Acid & 4.90 & Acid & 5.00 & Acid \\
\hline C-organic (\%) & 3.51 & High & 7.28 & Very high & 2.91 & Medium \\
\hline $\mathrm{N}(\%)$ & 0.25 & Medium & 0.39 & Medium & 0.22 & Medium \\
\hline $\mathrm{C} / \mathrm{N}$ ratio & 14.00 & Medium & 18.00 & High & 13.00 & Medium \\
\hline $\mathrm{P}_{2} \mathrm{O}_{5}(\mathrm{HCl} 25 \%)(\mathrm{mg} / 100 \mathrm{~g})$ & 17.00 & Low & 26.00 & Medium & 11.00 & Very low \\
\hline $\mathrm{K}_{2} \mathrm{O}(\mathrm{mg} / 100 \mathrm{~g})$ & 3.00 & Very low & 11.00 & Low & 6.00 & Very low \\
\hline $\mathrm{Ca}\left(\mathrm{cmol}_{\mathrm{c}} / \mathrm{kg}\right)$ & 0.44 & Very low & 1.68 & Very low & 0.46 & Very low \\
\hline $\mathrm{Mg}\left(\mathrm{cmol}_{\mathrm{c}} / \mathrm{kg}\right)$ & 0.26 & Very low & 1.03 & Medium & 0.51 & Low \\
\hline $\mathrm{K}\left(\mathrm{cmol}_{\mathrm{c}} / \mathrm{kg}\right)$ & 0.05 & Very low & 0.36 & Very low & 0.10 & Very low \\
\hline $\mathrm{Na}\left(\mathrm{cmol}_{\mathrm{c}} / \mathrm{kg}\right)$ & 0.08 & Very low & 0.15 & Medium & 0.23 & Low \\
\hline $\mathrm{KTK}^{*}\left(\mathrm{cmol}_{\mathrm{c}} / \mathrm{kg}\right)$ & 11.10 & Low & 20.35 & Medium & 10.61 & Low \\
\hline Base saturation (\%) & 8.00 & Very low & 17.00 & Very low & 13.00 & Very low \\
\hline $\mathrm{Al}^{3+}\left(\mathrm{cmol}_{\mathrm{c}} / \mathrm{kg}\right)$ & 3.75 & - & 3.28 & - & 3.12 & - \\
\hline Pyrite $\left(\mathrm{FeS}_{2}\right)$ & 0.15 & - & 0.06 & - & 0.03 & - \\
\hline
\end{tabular}

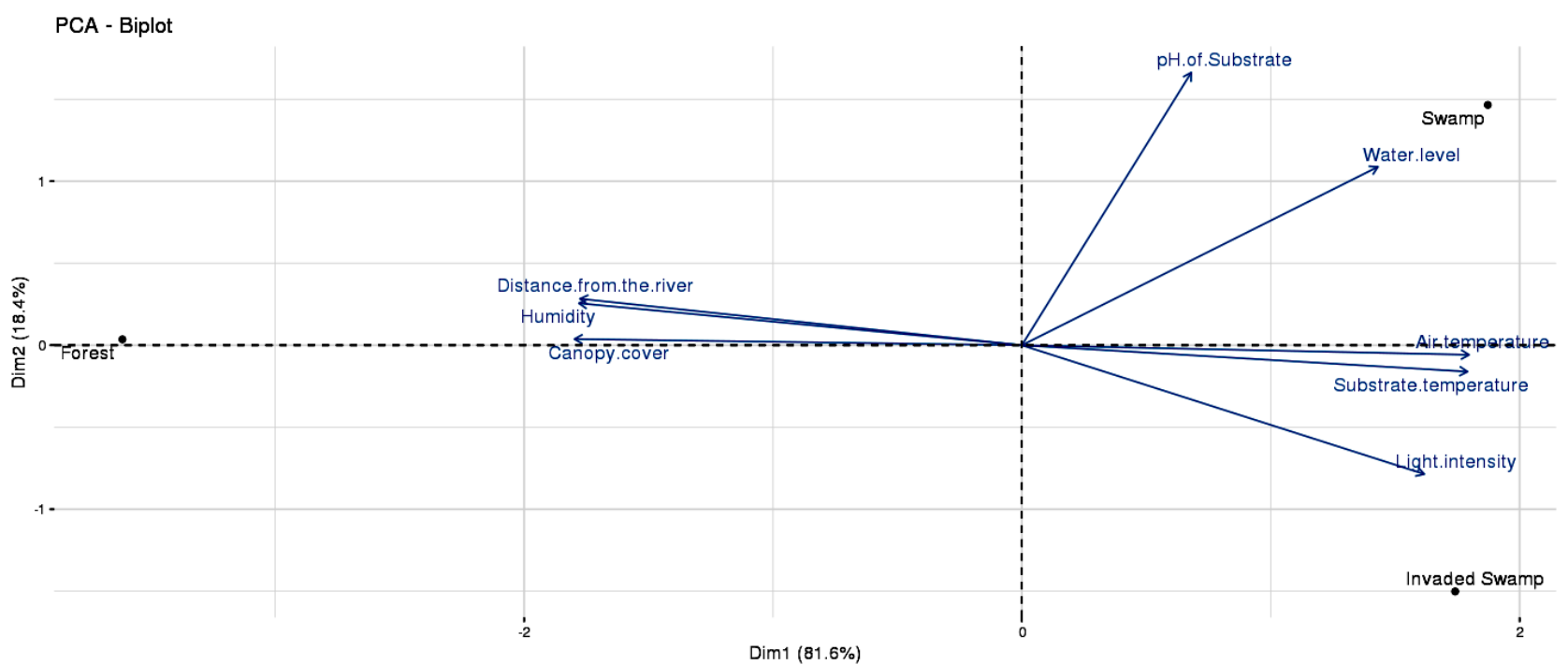

Figure 2. Interaction of three habitat conditions and environmental factors of Melastoma malabathricum invasion in the Way Kambas National Park, Lampung Province, Indonesia 


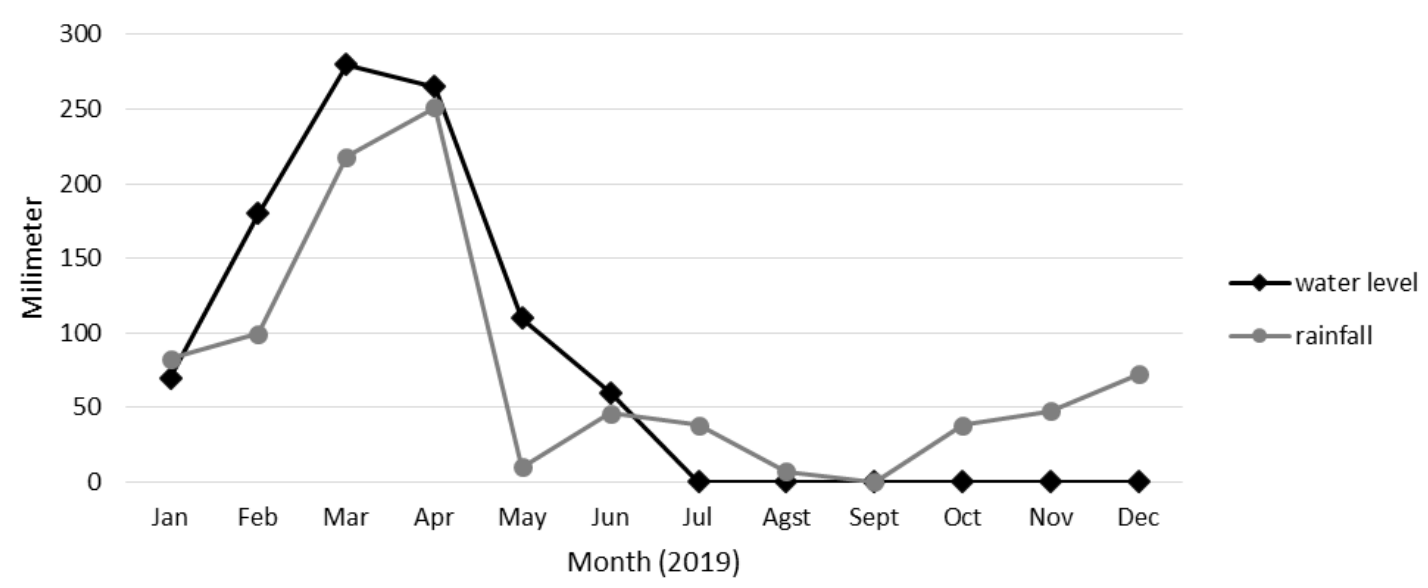

Figure 3. Kalibiru Swamp, Way Kambas National Park, Lampung Province, Indonesia average water level and monthly rainfall in the Lampung Province in 2019 (rainfall data source: BMKG 2020)

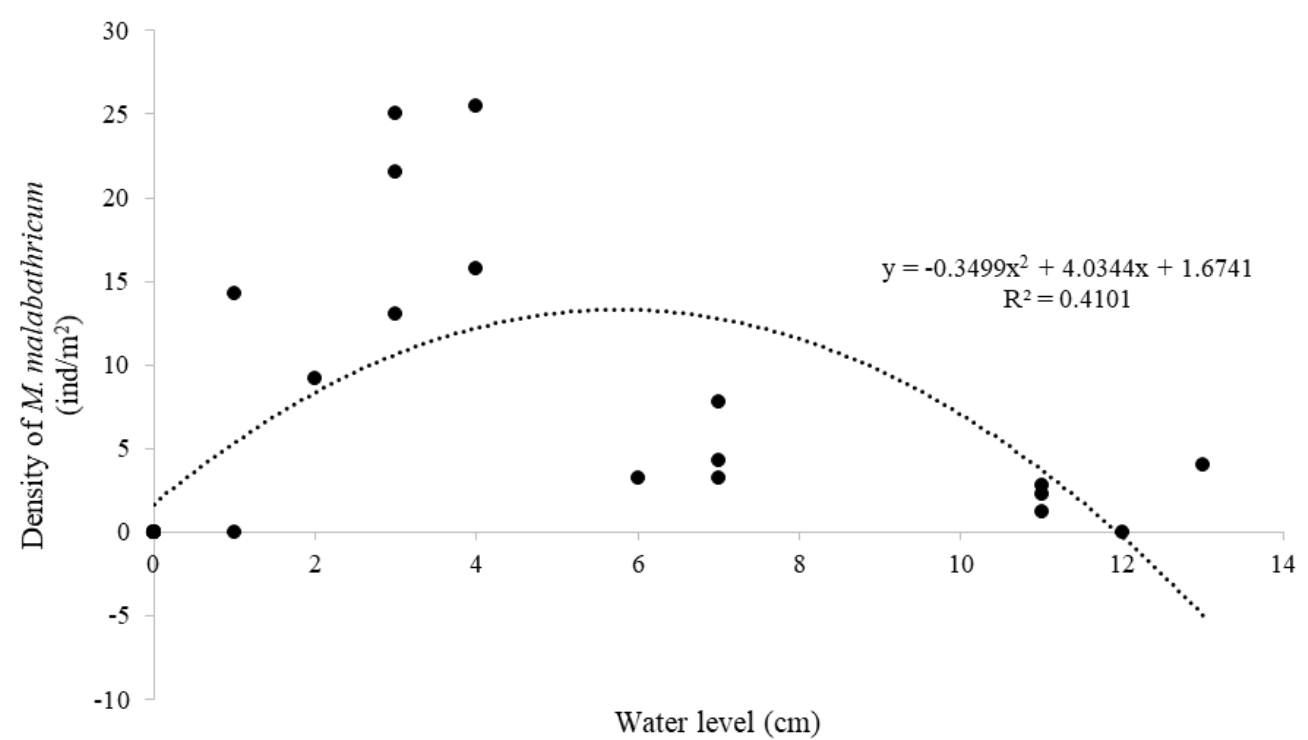

Figure 4. Quadratic regression between Melastoma malabathricum density and water level in the Kalibiru Swamp, Way Kambas National Park, Lampung Province, Indonesia

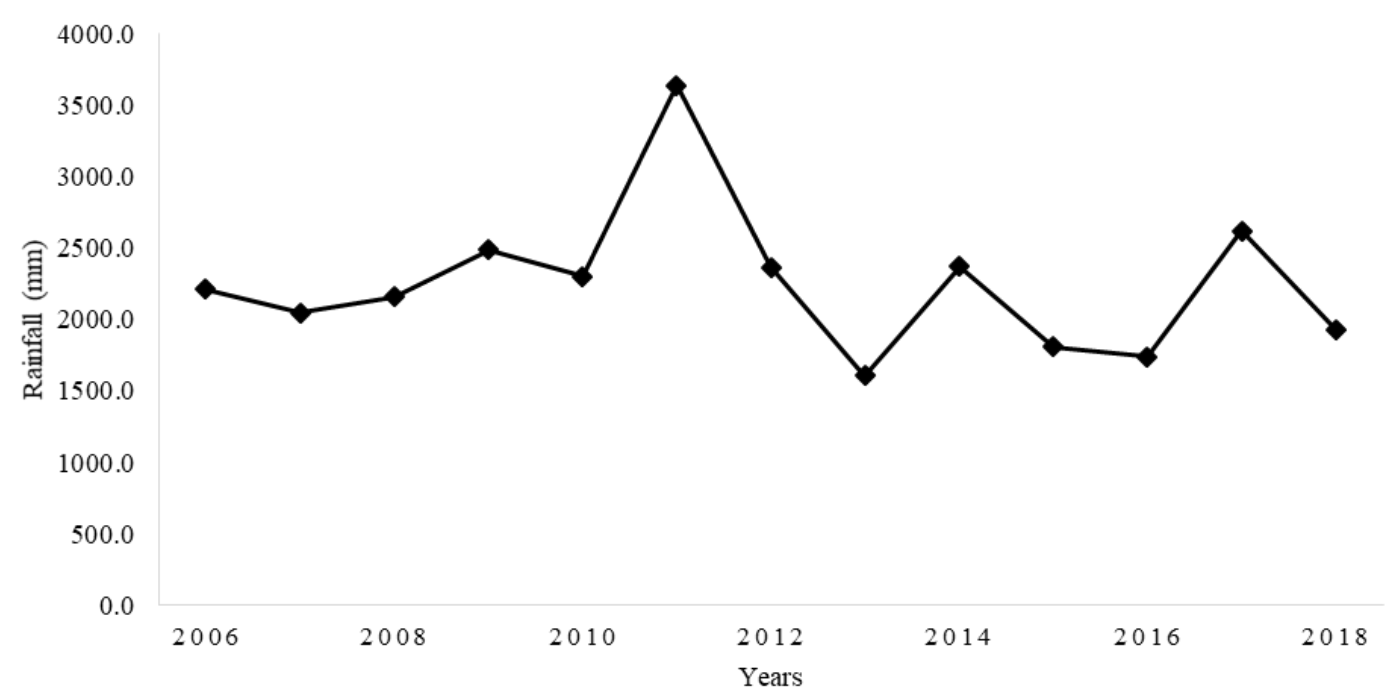

Figure 5. Annual rainfall in the Way Kambas National Park, Lampung Province, Indonesia (source: Special Agricultural Meteorological Station, PT. Great Giant Pineapple) 
Canopy cover is one of the limiting factors of $M$. malabathricum invasion, for example in Pangandaran Nature Reserve, M. malabathricum grows spread from the edge of the forest into open area (Rosleine and Suzuki 2012). The more closed the forest canopy, the lower the density of $M$. malabathricum. M. malabathricum requires full sunlight for its growth and reproduction. M. malabathricum seeds are not able to germinate in dark conditions. Besides that, the growth of M. malabathricum which is exposed to full sunlight will be better than those in shaded locations.

In conclusion, Melastoma malabathricum invaded and covered $88 \%$ of the Kalibiru Swamp in the WKNP, with a density of 30 individuals $/ \mathrm{m}^{2}$. M. malabathricum invasion in the WKNP was caused by biotic and abiotic factors. Biotic factors were from the ability of these plants to produce allelopathic chemicals, the absence of large trees that provide shade, and the role of animals, such as birds from the Pycnonotus family and a group of ferrets that spread the seeds of these plants. While the abiotic factors that cause invasion were poor soil conditions, higher $\mathrm{Al}^{3+}$ and pyrite contents $(3.75$ and $0.15 \mathrm{cmol} / \mathrm{kg})$, and lower $\mathrm{Mg}(0.26$ $\mathrm{cmol} / \mathrm{kg}$ ) compared with soils in non-invaded habitats, these conditions indicated the potential of the soil in invaded habitats to become more acidic. Other abiotic factors were the water level of the swamp that was less than $6 \mathrm{~cm}$ and the dryness of the swamp during the dry season, which gave $M$. malabathricum seeds the opportunity to grow and invade.

The presence of invasive plants in conservation areas generally causes negative impacts, therefore research on the impact of M. malabathricum invasion on WKNP and growth of $M$. malabathricum in WKNP needs to be controlled so that swamps in the conservation area can be good habitat for animals.

\section{ACKNOWLEDGEMENTS}

A gratitude is expressed to Yayasan Penyelamatan danKonservasi Harimau Sumatra (PKHS) of Way Kambas National Park, Lampung, Indonesia and Tropical Forest Conservation Action for Sumatra (TFCA-Sumatra) for facilitating this research so that this research can proceed as expected.

\section{REFERENCES}

Bambach RK, Bush AM, Erwin DH. 2007. Autecology and the filling of ecospace: Key metazoan radiations. Palaeontology 50 (1): 1-22. DOI 10.1111/j.1475-4983.2006.00611.x.

Broadbent A, Stevens CJ, Peltzer DA, Ostle NJ, Orwin KH. 2018 Belowground competition drives invasive plant impact on native species regardless of nitrogen availability. Oecologia 186 (2): 577587. DOI: $10.1007 / \mathrm{s} 00442-017-4039-5$
Claveria RJR, Perez TR, Perez REC, Algo JLC, Robles PQ. 2019. The identification of indigenous $\mathrm{Cu}$ and As metallophytes in the Lepanto $\mathrm{Cu}-\mathrm{Au}$ Mine, Luzon, Philippines. Environ Monit Assess 191 (3): 185. DOI: $10.1007 / \mathrm{s} 10661-019-7278-6$

Gallardo B, Clavero M, Sanchez MI, Vila M. 2016. Global ecological impacts of invasive species in aquatic ecosystems. Global Change Biol 22 (1): 151-163. DOI: $10.1111 / \mathrm{gcb} .13004$

Harvey JA, Fortuna TM. 2012. Chemical and structural effects of invasive plants on herbivore-parasitoid/predator interactions in native communities. Entomol Exp Appl 144 (1): 14-26. DOI: 10.1111/j.1570-7458.2012.01252.x

Hou QQ, Chen BM, Peng SL, Chen LY. 2014. Effects of extreme temperature on seedling establishment of nonnative invasive plants. Biol Invasions 16 (10): 2049-2061. DOI: 10.1007/s10530014-0647-8

Irwandi H, Pusparini N, Ariantono JY, Kurniawan R, Tari CA, Sudrajat A. 2018. The influence of ENSO to the rainfall variability in North Sumatra province. IOP Conf Ser Mater Sci Eng 335: 012055. DOI: 10.1088/1757-899X/335/1/012055.

Ismail D, Jiwan D. 2015. Browsing preference and ecological carrying capacity of sambar deer (Cervus unicolor brookei) on secondary vegetation in forest plantation. Anim Sci J 86 (2): 225-237. DOI: 10.1111/asj.12271

Isnaniarti UN, Ekyastuti W, Ekamawanti HA. 2017. Vegetation success in the gold mining land in Monterado District, Bengkayang District. Jurnal Hutan Lestari 6 (1): 198-207. DOI: 10.26418/jt.v7i1.22772 [Indonesian]

Jongman RHG, Ter Braak CJF, Van Tongeren OFR. 1987. Data Analysis in Community and Landscape Ecology. Pudoc, Wageningen.

Krebs CJ. 1989. Ecological Methodology. New York, Harper Collins Publiser Inc.

Ling KH, Kian CT, Hoon TC. 2009. A Guide to Medicinal Plants: An Illustrated, Scientific and Medicinal Approach. World Scientific, Singapore.

Ludwig JA, Reynolds JF. 1988. Statistical Ecology: A Primer on Methods \& Computing. John Wiley and Sons, New York.

Mahmud K, Burslem D. 2018. Contrasting growth responses to Al addition among populations of the $\mathrm{Al}$ hyper-accumulator $M$. malabathricum L. In: Jahan S, Mohamed NAB (eds). International Conference On Agriculture, Animal Sciences \& Food Technology 2018. University of Sultan Zainal Abidin, Terengganu, Malaysia, 3031 October 2018.

Master J. 2013. Ecological impact of Merremia peltata (L.) Merrill invasion on plant diversity at Bukit Barisan Selatan National Park. Biotropia 20 (1): 29-37. DOI: 10.11598/btb.2013.20.1.294

Padmanaba M, Tomlinson KW, Hughes AC, Corlett RT. 2017. Alien plant invasions of protected areas in Java, Indonesia. Sci Rep 7: 9334. DOI: 10.1038/s41598-017-09768-z.

Parrott S, Andrew P. 2011. An annotated checklist of the birds of Way Kambas National Park, Sumatra. Kukila 8: 57-85.

Rosleine D, Suzuki E. 2012. Secondary succession at abandoned grazing sites, Pangandaran Nature Reserve, West Java, Indonesia. Tropics 21 (3): 91-104. DOI: $10.3759 /$ tropics.21.91

Sarma D, Basumatary P, Datta BK. 2019. Allelopathic impact of Melastoma malabathricum L. on the seed germination and seedling growth of three agricultural crops. Indian Bot Soc 98 (3-4): 183-193. DOI: $10.5958 / 2455-7218.2019 .00021 .4$

Sutomo, Fardila D. 2015. Autecology of invasive species Cyperus rotundus L. in forest edge of Pohen Mountain, Batukahu Nature Reserve, Bali, Indonesia. Metamorfosa 2 (2): 50-57. DOI: 10.24843/metamorfosa.2015.v02.i02.p01

Walter GH, Hengeveld R. 2014. Autecology: Organisms, Interactions and Environmental Dynamics. CRC Press, New York.

Yustisi ALG, Riadi B, Suwarno Y, Purwono N. 2018. Spatial analysis of the correlation between hot spot distribution and land cover type in Sumatra, Indonesia. IOP Conf Ser Earth Environ Sci 165 (1): 1-9. DOI: $10.1088 / 1755-1315 / 165 / 1 / 012017$. 